\title{
The Bifunctional Catalase-Phenol Oxidase of Mycothermus Thermophilum (MtCATPO) Increases the Antioxidant Capacities of its Ortho-Diphenolic Substrates and of Green and Black Tea Extracts
}

\author{
Betül Söyler ${ }^{1, a, *}$, Zümrüt Begüm Ögel ${ }^{2, b}$ \\ ${ }^{1}$ Department of Food Engineering, Middle East Technical University, 06800 Ankara, Turkey \\ ${ }^{2}$ Department of Food Engineering, Konya Food and Agriculture University, 42080 Konya, Turkey \\ *Corresponding author \\ A R T I C L I N F O A B S T R A C T \\ Research Article \\ Catalase from the thermophilic fungus Mycothermus thermophilus is a bifunctional enzyme with a \\ secondary phenol oxidase activity (CATPO). MtCATPO catalyses the oxidation of catechol, \\ chlorogenic acid, caffeic acid and (+)-catechin to yield mainly dimers, and higher molecular weight \\ oligomers and polymers. The role of this phenol oxidase activity is not known. Here, the antioxidant \\ Received : 16/10/2020 \\ Accepted : 27/12/2020 \\ capacities (AC) of the phenolic substrates in the absence and presence of MtCATPO were \\ compared. The oxidized products displayed enhanced AC reaching a maximum of 2.4 -fold with \\ catechol. Other phenol oxidases (laccase and tyrosinase) did not yield AC enhancement to the same \\ extent. MtCATPO-treatment increased AC of green and black tea infusions, as well as water \\ extracts of samples collected from a black tea production line up to $28 \%$. The bifunctional \\ Keywords: \\ MtCATPO appears to be an important antioxidant enzyme with a wide range of potential \\ Catalase \\ applications in the food, neutraceuticals and pharmaceuticals industry.
}

Phenol oxidase

Phenolic compounds

Oxidation

Food phenolics

bsoyler@metu.edu.tr

\section{Introduction}

Catalase is one of the most important antioxidant enzymes. There are 3 classes of catalases, 1 . The monofunctional heme-containing catalases, 2. Hemecontaining catalase-peroxidases, and 3. Non-heme catalases (Zamocky et al., 2012). In recent years, a number of studies have shown that some of the monofunctional heme-containing catalases are 'not' monofunctional after all; namely, containing a secondary oxidase/peroxidase activity, in addition to the catalase activity (Loncar and Fraaije, 2015). Catalase degrades hydrogen peroxide $\left(\mathrm{H}_{2} \mathrm{O}_{2}\right)$ into water and oxygen and this acitivity is not only important from a biological point of view, but also finds several important industrial applications (Kaushal et al. 2018), including the removal of $\mathrm{H}_{2} \mathrm{O}_{2}$ from the fabric after bleaching treatment and semiconductor/circuit chip manufacturing $(\mathrm{Xu}, 2005)$ as well as from food products following cold pasteurisation.
Mycothermus thermophilus is a termophilic fungus constitutively producing an extracellular phenol-oxidase (Ögel et al., 2006), that was later identified as a bifunctional catalase with phenol oxidase activity, in the absence of $\mathrm{H}_{2} \mathrm{O}_{2}$ (Kocabas et al., 2008) (MtCATPO). MtCATPO is a heme-containing homotetramer with a total molecular mass of $320 \mathrm{kDa}$, and is the first catalase-phenol oxidase to be characterized in detail (Erçin, 2008; Kocabas et al., 2009; Yuzugullu et al. 2013).

The biological role of the phenol oxidase activity of $M$. thermophilus catalase is not known. In recent years a catalase-phenol oxidase from Amaranthus cruentus was identified (AcCATPO) and was shown to be involved in betalain biosynthesis (Xiao-Lu et al., 2016). Phenolic compounds are widely present in nature and display various biological functions including melanin biosynthesis (Eisenman and Casadevall, 2012). $M$. thermophilus contains a substantial amount of melanin 
(Ellis, 1982; Lyons and Sharma, 1998). Generation of $\mathrm{H}_{2} \mathrm{O}_{2}$ during melanin biosynthesis (Sevindik et al., 2017; Mohammed et al., 2020) has been demonstrated to occur as a result of reactions coupled to the enzymatic formation of $o$-quinones and the auto-oxidation of $o$-diphenols and other intermediates (Munoz-Munoz, 2009). MtCATPO both eliminates $\mathrm{H}_{2} \mathrm{O}_{2}$ and oxidizes $o$-diphenols into mainly dimers but also trimers, tetramers, oligomers and polymers (Ögel et al., 2006) and eventually these forms dark brown to black-coloured precipitates (Soyler, 2012). Thus, the enzyme is likely to have a role in melanin biosynthesis, which remains to be discovered (Pavan et al, 2019).

In order to explore the possible role of MtCATPO in the antioxidant mechanism of the fungus, in this study, the antioxidant capacities (AC) of substrates catechol, caffeic acid, chlorogenic acid, and (+)-catechin were analysed following oxidation by MtCATPO and were compared with the $\mathrm{AC}$ of the unreacted phenolic compounds.

Tea (Camelia sinensis (L.) Kuntze) is a popular beverage consumed both hot and cold and both in a fermented (black tea) and non-fermented (green tea) form. Tea is a valuable source of antioxidant phenolic compounds (Zhao et al., 2019). Northern Black Sea region of Turkey is well-known for its climate that allows the tea plantations (Camelia sinensis) and most tea manufacturing factories are located around Rize. It was of further interest in this study to apply MtCATPO on tea infusions, as well as samples taken from a tea manufacturing line, in order to see if there will be any improvement on the $\mathrm{AC}$ of the tea water extracts.

\section{Materials and Methods}

\section{Materials}

All phenolic compounds used as substrate were obtained from Sigma-Aldrich (Germany) or Merck (Germany). All organic solvents used were of analytical grade and obtained from Sigma, Fluka or AppliChem. ABTS (2,2'-azino-bis (3-ethyl benzothiazoline-6sulphonic acid)), trolox (6-hydroxy-2,5,7,8tetramethylchroman-2-carboxylic acid), TPTZ (2,4,6tris(2-pyridyl)-s-triazine), sodium acetate trihydrate $\left(\mathrm{CH}_{3} \mathrm{COONa} 3 \mathrm{H}_{2} \mathrm{O}\right)$, ferric chloride hexahydrate $\left(\mathrm{FeCl}_{3} \cdot 6 \mathrm{H}_{2} \mathrm{O}\right)$ were obtained from Sigma or Merck. All other chemicals, as well as the Agaricus bisporus (J.E. Lange) Imbach tyrosinase (1000 unit/mg) (1.14.18.1) and Trametes versicolor (L.) Lloyd laccase (10 unit $/ \mathrm{mg}$ ) (1.10.3.2) were purchased from Sigma-Aldrich.

The Mycothermus thermophilus (type culture Humicola insolens Cooney and R. Emers) industrial strain was provided by ORBA Inc., İstanbul (Simbiyotek Biyolojik Ürünler San. Tic. A.Ş.).

\section{Methods}

\section{CATPO Purification}

$M$. thermophilus was grown as described by Kocabas et al. (2008) at $45^{\circ} \mathrm{C}$ for 5 days on glucose $(40 \mathrm{~g} / \mathrm{L})$ containing YpSs broth (yeast extract, $4.0 \mathrm{~g}$; K2HPO4, 1.0 $\mathrm{g}$; $\mathrm{MgSO} 4.7 \mathrm{H} 2 \mathrm{O}, 0.5 \mathrm{~g}$; in 11 distilled water) and culture supernatants were used for the purification of CATPO. Enzyme purification was performed with an AKTA Prime FPLC system (Amersham Biosciences, USA). All buffers were filtered through $0.45 \mu \mathrm{m}$-pore-size membrane
(Millipore, USA) before use. Anion exchange was performed using $20 \mathrm{~mL}$ prepacked HiPrep 16/60 Q XL column (Amersham Biosciences, USA) with $50 \mathrm{mM}$ Tris$\mathrm{HCl}(\mathrm{pH} 8.0)$ at $2 \mathrm{~mL} / \mathrm{min}$ flow rate. Enzyme was eluted as $3 \mathrm{~mL}$ fractions with a $0-1.0 \mathrm{M} \mathrm{NaCl}$ gradient in the same buffer. All fractions were checked for both catalase and phenol oxidase activities. CATPO-active fractions were concentrated using a $10 \mathrm{~K}$ centrifugal concentrator (Amicon, USA) and loaded on a prepacked HiPrep 16/60 Sephacryl S-100 High Resolution gel filtration column (Amersham Biosciences, USA) equilibrated with $50 \mathrm{mM}$ Tris- $\mathrm{HCl}$ (pH 8.0). Eluate (400 mL) was collected as $3 \mathrm{~mL}$ fractions at $1 \mathrm{~mL} / \mathrm{min}$ flow rate. Protein concentrations were determined according to the Bradford method (Bradford, 1976) by using bovine serum albumin (BSA) as a standard (Kocabas et al., 2008). Catalase and phenol oxidase acitivities were measured before purification and total protein concentration data was collected in each step.

Phenol Oxidase Assay

Extracellular phenol oxidase activity measurements were determined using a SHIMADZU UV-1700 PharmaSpec temperature-controlled spectrophotometer set to $60^{\circ} \mathrm{C}$. Enzyme activity was followed by examining the increase in absorbance at $420 \mathrm{~nm}$ of the reaction mixture. The reaction mixture consisted of $0.5 \mathrm{~mL} 100 \mathrm{mM}$ catechol solution in $100 \mathrm{mM}$ phosphate buffer ( $\mathrm{pH}$ 7.0) as substrate, $0.5 \mathrm{~mL}$ enzyme solution and $1 \mathrm{~mL} 100 \mathrm{mM}$ phosphate buffer at $\mathrm{pH}$ 7.0. The substrate solution was prepared fresh in pre-incubated buffer and used directly to minimize the effects of rapid auto-oxidation of catechol with molecular oxygen in the air. Both buffer and enzyme solutions were pre-incubated for 5 minutes at $60^{\circ} \mathrm{C}$. All activity measurements were contrasted to an enzyme blank sample, where $0.5 \mathrm{~mL} 100 \mathrm{mM}$ phosphate buffer ( $\mathrm{pH}$ 7.0) was added instead of enzyme solution. Enzyme activity was determined by the formula given in Ögel et al. (2006).

All the measurements were performed in triplicate. Reactions were performed at the optimal temperature and $\mathrm{pH}$ conditions of the enzyme activities, for one hour. Therefore, the conditions were the same for tyrosinase and laccase, except temperature and $\mathrm{pH}$; namely, at $25^{\circ} \mathrm{C}$ and $\mathrm{pH} 6.5$ for tyrosinase and at $25^{\circ} \mathrm{C}$ and $\mathrm{pH} 4.8$ for laccase.

\section{Catalase Assay}

Catalase activity was measured by the method of Beers and Sizer (1952) in a $50 \mathrm{mM}$ potassium phosphate solution buffer. The substrate was prepared by adding $10 \mu \mathrm{L}$ of a freshly prepared $30 \% \mathrm{H}_{2} \mathrm{O}_{2}$ solution to $10 \mathrm{~mL}$ buffer followed by vortexing yielding a final concentration of $0.32 \mathrm{~g} \mathrm{H}_{2} \mathrm{O}_{2}$ per liter solution. $1.5 \mathrm{~mL}$ of substrate solution was taken and its optical density was followed in an UV spectrophotometer (SHIMADZU UV-1700) at $240 \mathrm{~nm}$ wavelength.

\section{Phenol Oxidation}

Catechol, (+)-catechin, chlorogenic acid and caffeic acid were oxidized by dissolving the 4 substrates in $2 \mathrm{~mL}$ methanol and mixing them with $1 \mathrm{~mL}$ pure enzyme $(3.63$ $\mathrm{U} / \mu \mathrm{g}$ ) in $2 \mathrm{~mL} 100 \mathrm{mM}$ potassium phosphate buffer at $\mathrm{pH}$ 7.0. Reaction temperature was adjusted to $60^{\circ} \mathrm{C}$. Product formation was analyzed by high performance liquid chromatography (HPLC) at $1 \mathrm{~h}$. Following purification, MtCATPO (15 U) was added into $2 \mathrm{~mL}$ of $10 \mathrm{mM}$ phenolic substrate dissolved in methanol/ethanol, $2.5 \mathrm{~mL}$ phosphate buffer $\mathrm{pH}$ 7.0. 


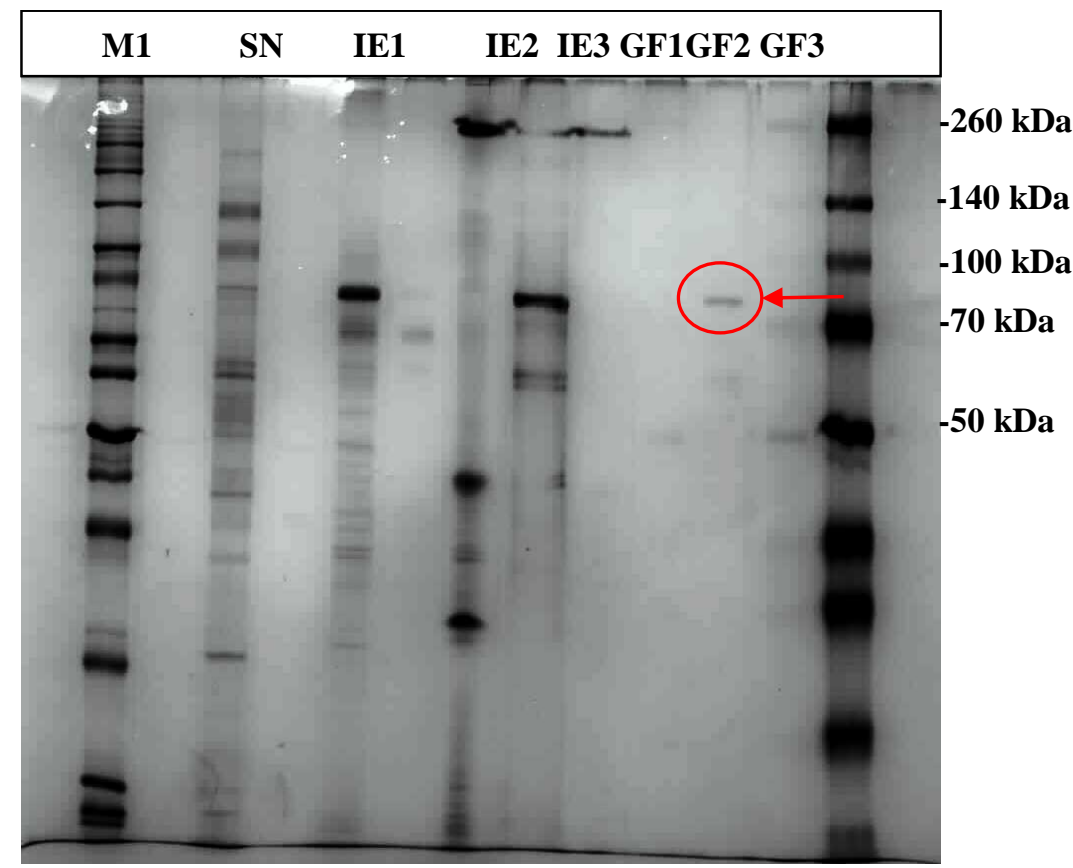

Figure 1.

Enzymatic reactions took place at $60^{\circ} \mathrm{C}$ and were terminated after 1 hour. Antioxidant capacity measurements were performed afterwards using these reactions.

T. versicolor laccase was used to set up oxidation reactions for the antioxidant activity assays. 10-unit enzyme was added into $2 \mathrm{~mL} 0.1 / 1 / 10 \mathrm{mM}$ phenolic substance dissolved in methanol/ethanol. Then, $3 \mathrm{~mL} 100$ $\mathrm{mM}$ sodium acetate buffer $(\mathrm{pH}=4.8)$ was added and the reactions were carried out for an hour in $30^{\circ} \mathrm{C}$ water bath.

10 units of $A$. bisporus tyrosinase was added into $2 \mathrm{~mL}$ of $0.1 / 1 / 10 \mathrm{mM}$ phenolic substance dissolved in methanol/ethanol and $3 \mathrm{~mL} 100 \mathrm{mM}$ pH 6.5 potassium citrate buffer were added into the reaction tube and kept for $1 \mathrm{~h}$ at $25^{\circ} \mathrm{C}$. All reactions were performed in triplicates.

\section{Preparation of Tea Samples}

Fresh tea leaves and samples from each production stage (harvested fresh tea leaves, after rolling, before fermentation, after fermentation, and after drying) were kindly provided by Doğuş Çay. The tea leaves were harvested during mid- June from Rize. Infusions were prepared by adding $2 \mathrm{~g}$ of dry tea to $200 \mathrm{~mL}$ boiling deionized water $\left(90 \pm 5^{\circ} \mathrm{C}\right)$ by the $1 \%$ rule (Borse and Jagan Mohan Rao, 2012). The resulting infusions were stirred with a glass rod for about $30 \mathrm{~s}$ to ensure proper wetting, covered and steeped for 3, 5 and 10 minutes brewing times (Peterson et al., 2005). The steeped infusions were then immediately filtered through Whatman filter paper to remove contact with the tea leaves and allowed to cool to $60^{\circ} \mathrm{C}$. For MtCATPO treatment, $15 \mathrm{U}$ of enzyme $/ \mathrm{mL}$ was added and samples were kept at $60^{\circ} \mathrm{C}$ for one hour. Thereafter, AC were determined using the TEAC method. Each measurement was made in triplicates.

Determination of Total Antioxidant Activities

Two methods were used for total antioxidant activity determinations, namely 2,2'-azino-bis (3ethylbenzothiazoline-6-sulfonic acid (ABTS) - based TEAC method (Re et al., 1999) and Ferric Reducing Antioxidant Power (FRAP) (Benzie and Strain, 1996). The standard TEAC assay was been used with minor modifications for determination of the TEAC value. A stable stock solution of ABTS was made by reacting a 7 $\mathrm{mmol} / \mathrm{L}$ aqueous solution of ABTS with $2.45 \mathrm{mmol} / \mathrm{L}$ potassium persulfate and allowing the mixture to stand in the dark at room temperature for 12-16 h before use. The concentrated $\mathrm{ABTS}^{+}$solution was diluted with ethanol or methanol to a final absorbance of $0.70 \pm 0.02$ at $734 \mathrm{~nm}$ at room temperature. A reaction mixture containing ABTS and Trolox (concentration range, $0-50 \mu \mathrm{mol} / \mathrm{L}$ ) was incubated for 4 minutes, 6 minutes, or 10 minutes and subjected to spectrophotometric measurements. $10 \mu \mathrm{L}$ of each sample prepared at different concentrations was mixed with were $1000 \mu \mathrm{L}$ ABTS + solution and the absorbance were read at $734 \mathrm{~nm}$. This was compared to a blank where $10 \mu \mathrm{L}$ of the solvent was added to $1000 \mu \mathrm{L}$ of the $\mathrm{ABTS}^{+}$solution. The reduction in absorbance 6 minutes after addition of the antioxidant was determined.

The FRAP assay utilizes antioxidants as reductants in a redox-linked colorimetric method. At low $\mathrm{pH}$, reduction of ferric tripyridyl triazine (Fe III TPTZ) complex to ferrous form was monitored by measuring the change in absorption at $593 \mathrm{~nm} .3 \mathrm{~mL}$ working FRAP reagent [(a) Acetate buffer $300 \mathrm{mM}$ pH 3.6 was prepared by weighing $3.1 \mathrm{~g}$ sodium acetate trihydrate $\left(\mathrm{CH}_{3} \mathrm{COONa} 3 \mathrm{H}_{2} \mathrm{O}\right)$ and adding $16 \mathrm{~mL}$ of glacial acetic acid to make the volume to $1 \mathrm{~L}$ with distilled water. (b) TPTZ (2, 4, 6-tripyridyl-s- triazine) (MW 312.34) $10 \mathrm{mM}$ in 40mM HCl (MW 36.46) (c) $\mathrm{FeCl}_{3}$ $6 \mathrm{H}_{2} \mathrm{O}$ (MW 270.30) $20 \mathrm{mM}$. The working FRAP reagent was prepared by mixing $\mathrm{a}, \mathrm{b}$ and $\mathrm{c}$ in the ratio of 10: $1: 1$ at the time of use] was mixed with $100 \mu \mathrm{L}$ sample and absorbance at $593 \mathrm{~nm}$ was measured at $\mathrm{t}=0$ minute after thorough vortexing. Thereafter, samples were placed at $37^{\circ} \mathrm{C}$ in water bath and absorption was again measured after 4 minutes.

All data were statistically analyzed by one-way ANOVA followed by student $t$-test. In all cases, $p$-values $\leq 0.05$ were considered statistically significant. 
a
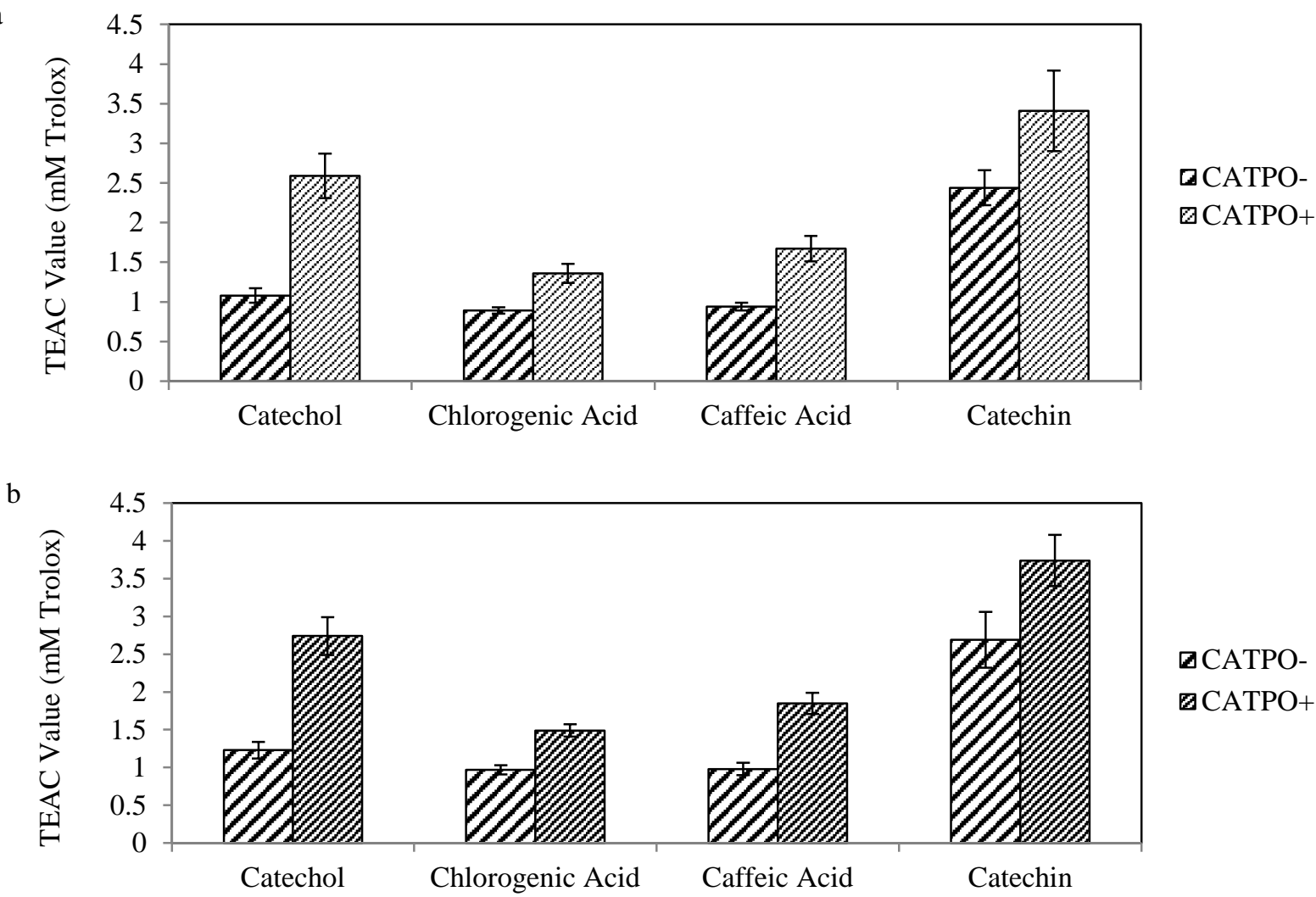

Figure 2.

a

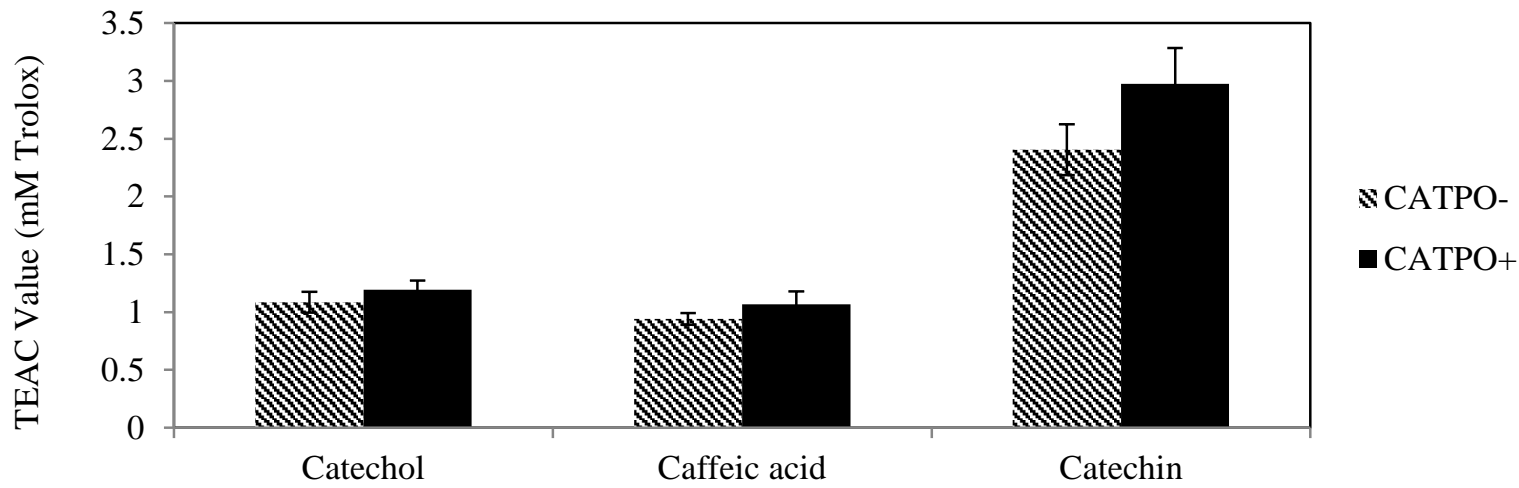

b

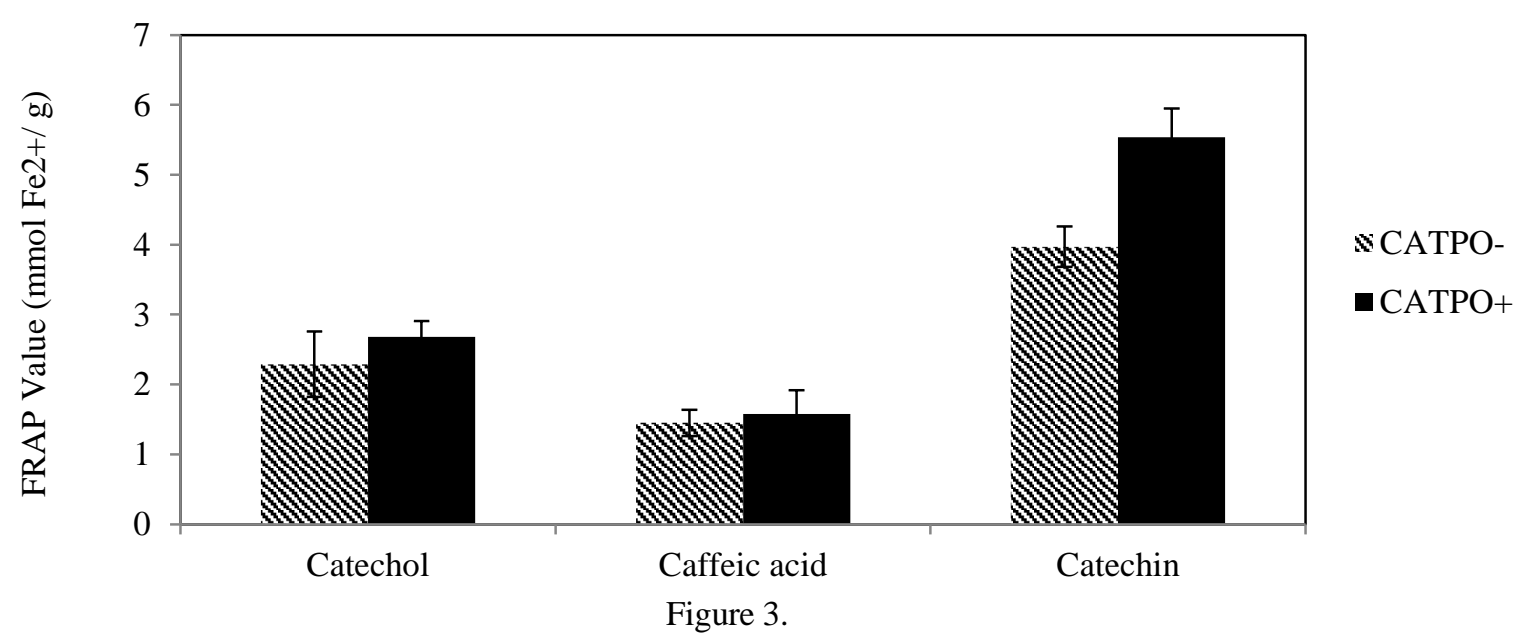




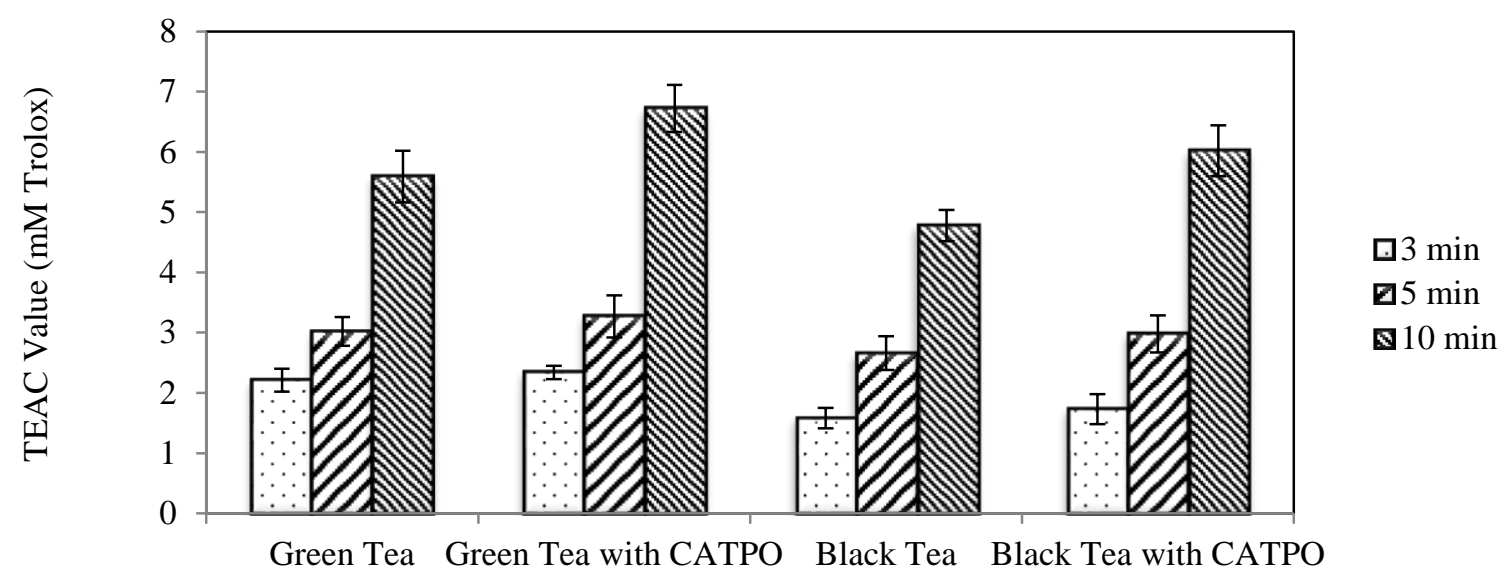

Figure 4.

Table 1. Two-step purification of MtCATPO by ion-exchange chromatography and gel filtration

\begin{tabular}{l|ccccccc}
\hline & $\begin{array}{c}\text { Volume } \\
(\mathrm{mL})\end{array}$ & $\begin{array}{c}\text { Activity } \\
(\mathrm{U} / \mathrm{mL})\end{array}$ & $\begin{array}{c}\text { Total Activity } \\
(\mathrm{U})\end{array}$ & $\begin{array}{c}\text { Total Protein } \\
(\mathrm{mg})\end{array}$ & $\begin{array}{c}\text { Specific Activity } \\
(\mathrm{U} / \mathrm{mg})\end{array}$ & $\begin{array}{c}\text { Yield } \\
(\%)\end{array}$ & $\begin{array}{c}\text { Purification } \\
\text { Fold }\end{array}$ \\
\hline Supnt & 50 & 28 & 1400 & 1.8 & 778 & 100 & 1 \\
IE* $^{*}$ & 10 & 22 & 220 & 0.25 & 880 & 16 & 1.13 \\
GF** $^{*}$ & 5 & 30 & 150 & 0.035 & 4285 & 11 & 5.5 \\
\hline
\end{tabular}

*Ion Exchange Chromatography. **Gel Filtration

Table 2. Antioxidant capacities of MtCATPO- treated and untreated samples from a black tea production line

\begin{tabular}{l|cc}
\hline \multicolumn{1}{c|}{ Stage of Production } & TEAC value (nM Trolox) & Fold Increase \\
\hline STAGE 1 & & \\
\hline Fresh tea leaves & $4.57 \pm 0.36$ & $1.13^{*}$ \\
CATPO- treated fresh tea leaves & $5.16 \pm 0.41$ & $1.13^{*}$ \\
STAGE 2 & $4.40 \pm 0.29$ & \\
\hline Tea leaves after rolling & $4.98 \pm 0.33$ & $1.15^{*}$ \\
CATPO- treated tea leaves after rolling & & \\
STAGE 3 & $4.25 \pm 0.38$ & $1.13^{*}$ \\
Tea leaves just before fermentation & $4.87 \pm 0.26$ & \\
CATPO- treated tea leaves just before fermentation & $3.72 \pm 0.22$ & \\
STAGE 4 & & $4.21 \pm 0.30$ \\
\hline Tea leaves after fermentation & & $1.28^{*}$ \\
CATPO- treated tea leaves after fermentation & $3.05 \pm 0.21$ \\
STAGE 5 & $3.89 \pm 0.25$ & \\
\hline Tea leaves after drying & & \\
CATPO- treated tea leaves after drying & & \\
\hline
\end{tabular}

\section{Results and Discussion}

\section{Purification of MtCATPO}

The M. thermophilus bifunctional catalase-phenol oxidase (MtCATPO) was purified as described in the materials and methods. The SDS-PAGE result (Figure 1) shows the purified $80 \mathrm{kDa}$ monomer.

Total protein, total and specific activities and fold purifications are presented in Table 1. Based on the presented data, MtCATPO was successfully purified at 30 $\mathrm{U} / \mathrm{mL}$ for further use in the oxidation of phenolic compounds and the tea samples.

Antioxidant Capacities of MtCATPO- Oxidized Phenolic Products

The antioxidant capacities (AC) of MtCATPO oxidized substrates catechol, catechin, caffeic acid and chlorogenic acid were first analyzed by the TEAC method both by using methanol and ethanol as the solvent (Figure 2 aandb). Reactions were performed under optimal conditions, as described in the materials and methods. Two different solvents were used in the reactions, ethanol and methanol. The TEAC values of the unreacted substrates were close to those in the literature (Re et al., 1999; Rice Evans et al., 1997; Pelegrini et al., 2000; Arts et al., 2000).

Accordingly, oxidation of the phenolic substrates by MtCATPO resulted in a significant increase in the antioxidant capacities of the products (Figure $2 \mathrm{a}$ and $\mathrm{b}$ ). Catechol resulted in a surprisingly high increase of c.2.4 fold in the presence of methanol, which was followed by caffeic acid (c. 1.9-fold), chlorogenic acid (c. 1.5-fold) and (+)-catechin (c. 1.4-fold). Reactants were dissolved more 
easily in methanol; therefore, methanol was the choice of solvent for the rest of the study. Experiments were repeated, this time using the FRAP method, which yielded similar results using methanol as the solvent (results not shown).

Such an increase in AC as a result of enzymatic phenol oxidation is new to the literature. It was, therefore, of interest to analyze the effect of the well-known phenol oxidases, laccase (from $T$. versicolor) and tyrosinase (from A. bisporus) on the AC of the same phenolic compounds, in order to see if this result was unique to MtCATPO or not. According to the results, not all substrates were oxidized by these enzymes. Laccase oxidized catechol, catechin and caffeic acid but not chlorogenic acid. Interestingly, as opposed to MtCATPO, catechol oxidation did not result in a significant increase in the AC of catechol. Catechin (c. 1.3-fold) and caffeic acid (c. 1.1-fold) AC showed a significant increase, albeit lower than those obtained by MtCATPO (Figure $3 \mathrm{a}$ and b). Tyrosinase oxidized catechol and catechin, while caffeic acid and chlorogenic acid were not oxidized. A slight increase in the AC of catechol nor catechin were observed, however, these were statistically insignificant (Data not shown).

Based on the above results MtCATPO is very efficient in enhancing the AC of catechol as well as its other $o$ diphenolic substrates, which is not observed for laccase and tyrosinase to the same extent for the same substrates. These $o$-dipehnolic compounds are among those with highest AC (Farooqi and Farooqi, 2010). Thus, the role of MtCATPO may be to convert these phenolics into higher molecular weight compounds that are both more stable and have higher $\mathrm{AC}$, while eliminating any $\mathrm{H}_{2} \mathrm{O}_{2}$ that may have generated in the environment. Such a scenario would fit rather well to melanin biosynthesis, which is known as an anti-stress agent (Eisenman and Casadevall, 2012) besides its plenty of other functions and $\mathrm{H}_{2} \mathrm{O}_{2}$ is generated during its biosynthesis as mentioned (Munoz-Munoz et al., 2012). Nonetheless, these results qualify MtCATPO as an excellent antioxidant enzyme with myriad possible applications, including the enhancement of $\mathrm{AC}$ of food products rich in terms of phenolic compounds, such as tea (Silva and Pogačnik, 2020).

Antioxidant Capacities of CATPO- Treated Green and Black Tea Unfusions

Both green and black tea $(C$. sinensis) are valuable as strong antioxidants and have also been studied extensively as cancer chemopreventive agents (Henning et al., 2004). Tea is a traditional popular beverage in many parts of the world since ancient times.

Based on the above results, it was of interest to analyze the AC-enhancement effect of MtCATPO in tea, in order to see its effect in a complex food environment. Green tea is rich in catechins whereas black tea is a rich source of theaflavins. It has been shown that both are equally effective antioxidants (Leung et al., 2001) despite of the fact that the catechins in green tea are oxidized by the phenol oxidases, released upon crushing the leaves during the enzymatic fermentation process of black tea.

MtCATPO was added to the green and black tea infusions as described in the materials and methods. According to the results (Figure 4), the AC capacities of the samples increased as the brewing time increased. At 10 min brewing, the AC were 2.5 to 3 -fold higher than the 3 min brewing samples. MtCATPO treatment significantly increased $\mathrm{AC}$ of both green and black tea infusions that were brewed for 5 and $10 \mathrm{~min}$, but not at $3 \mathrm{~min}$. The maximum fold increase in the antioxidant capacity was $c$. 1.26-fold, obtained for 10 minutes brewing of black tea.

Green tea resulted in higher $\mathrm{AC}$, however the $\mathrm{AC}$ enhancement by MtCATPO was almost the same for green and black tea. The fact that green tea contains catechins whereas black tea contains the theaflavins which are products of the oxidation of catechins, suggests that the bifunctional MtCATPO enhances the free-radical scavenging activities of the products irrespective of prior enzymatic fermentation. The mechanism of this AC enhancement is interesting and deserves further studies.

\section{Effect of MtCATPO on the Antioxidant Capacities of} Tea Leaves Collected from the Tea Production Line

The observation of an increase in the AC of tea infusions raised the question of whether MtCATPO could be employed during the manufacture of black tea, such as the fermentation step. Tea has been shown to be an effective antioxidant both in vitro and in vivo (Serafini et al., 1996) and is widely consumed in Turkey and many parts of the world. In Turkey, black tea is traditionally consumed at breakfast and at any time of the day, before and after meals. Turks have developed a different kind of brewing technique where the teapot is placed on the top of a kettle and tea is brewed by the heat of the steam. Just like Turkish coffee, brewing delicious tea is highly prestigious and almost an art.

Tea samples were obtained from a production plant in Rize, which is the most important location for tea plantations. Samples from the different stages of tea production were used immediately after being received from the production area on dry ice, no further chopping were done. Standard brewing time was selected as 5 minutes and water extractions and enzyme treatments were performed as described for green and black tea infusions. Samples were immediately subjected to AC determination without storage.

Based on the results presented in Table 2, MtCATPO significantly increases the AC of phenolic compounds in tea leaves collected from the different stages of tea production with a fold increase of 1.13 to 1.26 . Experiments were repeated for laccase and tyrosinase, however, these enzymes failed to increase the AC of the tea samples.

Accordingly, MtCATPO can be applied to tea either during production or directly into the beverage prior to consumption for AC enhancement. In practice the best stage of enzyme-treatment would be the incorporation of CATPO during fermentation. In fact, this could be the ability of the enzyme to increase AC does not only occur with the pure substrates but also in complex phenolic environments such as tea. This capability of MTCATPO appears to be unique, and is not attained by laccase and tyrosinase treatments.

Based on the results, MtCATPO can be regarded as an important antioxidant enzyme, not just due to its catalase activity but also due to its capability of increasing the AC of the phenolic oxidation products generated. MtCATPO can be employed as a functional enzyme for increasing the 
AC of food products, at the same time, consuming the $\mathrm{H}_{2} \mathrm{O}_{2}$ that is generated by oxidation, or that is added into the medium for antimicrobial purposes. The oligomers generated by oxidation are also likely to present antimicrobial activity, opening the possibility of a whole range of biopreservation and biocidal applications in food, agriculture and forestry. Future studies will focus on the possible functional properties of the oxidized products, including anti-microbial, anti-ageing and anti-cancer properties

\section{References}

Arts IC, Van De Putte B, Hollman PC. 2000. Catechin contents of foods commonly consumed in The Netherlands 2. Tea, wine, fruit juices, and chocolate milk, Journal of Agricultural Food Chemistry, 48: 1752-1757.

Bradford MM. 1976. A rapid and sensitive method for the quantitaion of microgram quantities of protein utilizing the principle of protein-dye binding. Analytical Biochemistry, 72: 248-254.

Beers RF and Sizer IW. 1952. A spectrophotometric method for measuring the breakdown of hydrogen peroxide by catalase. Journal of Biological Chemistry, 195: 133-140.

Benzie IFF and Strain JJ. 1996. The ferric reducing ability of plasma (FRAP) as a measure of "antioxidant power": The FRAP assay. Analytical Biochemistry. 239: 70-76.

Borse BB and Jagan Mohan Rao L. 2012. Novel bio-chemical profiling of Indian black teas with reference to quality parameters. Journal of Bioequivalence \& Bioavailability, 14: $1-16$.

Eisenman HC and Casadevall A. 2012. Synthesis and assembly of fungal melanin. Appl. Microbiological Biotechnology. 93(3): 931-940.

Ellis DH. 1982. Ultrastructure of thermophilic fungi V. Conidial ontogeny in Humicola grisea var. thermoidea and H. insolens. Transactions of British Microbiological Society, 78(1): 129139.

Erçin HÖ. 2008. Cloning of the Scytalidium thermophilum bifunctional catalase/phenol oxidase gene and expression in Aspergillus sojae. M.S. Thesis, Middle East Technical University, $114 \mathrm{p}$.

Farooqi T and Farooqi AA. 2010. Molecular mechanism underlying the therapeutic activities of propolis: A critical review. Current Nutrition and Food Science, 6(3): 1-15.

Henning SM, Niu Y, Lee NH. 2004. Thames GD, Minutti RR, Wang H, Go, VLW, Heber D. Bioavailability and antioxidant activity of tea flavonols after consumption of green tea, black tea, or green tea extract supplement. The American Journal of Clinical Nutrition, 80: 1558-1564.

Loncar N and Fraaije MW. 2015. Catalases as biocatalysts in technical applications: Current state and perspectives, Applied Microbiology and Biotechnology, 99: 3351-3357.

Lyons GA and Sharma S. 1998. Differentiation of Scytalidium thermophilum isolates by thermogravimetric analyses of their biomass. Mycological Research, 102(7):843-849.

Kaushal J, Mehandia S, Singh G, Raina A, and Arya SK. 2018. Catalase enzyme: Application in bioremediation and food industry. Biocatalysis and Agricultural Biotechnology, 16: 192-199.

Kocabas DS, Bakir U, Phillips SEV, McPherson MJ and Ogel ZB. 2008. Purification, characterization, and identification of a novel bifunctional catalase-phenol oxidase from Scytalidium thermophilum, Applied Microbiology Biotechnology, 79: 407-415.
Kocabas DS, Pearson AR, Phillips SEV, Bakir U, Ogel ZB, McPherson MJ, Trinh CH. 2009. Crystallization and preliminary X-ray analysis of a bifunctional catalase-phenol oxidase from Scytalidium thermophilum. Acta Crystallographica. Section F, Structural Biology Communications, F65: 486-488.

Mohammed FS, Şabik AE, Sevindik E, Pehlivan M, Sevindik M. 2020. Determination of Antioxidant and Oxidant Potentials of Thymbra spicata Collected from Duhok-Iraq. Turkish Journal of Agriculture-Food Science and Technology, 8(5): 1171-1173.

Munoz-Munoz JL, Garcia-Molina F, Varon R, Tudela J, GarciaCanovas F, Rodriguez-Lopez JN. 2009. Generation of hydrogen peroxide in the melanin biosynthesis pathway. Biochimica et Biophysica Acta,1794: 1017-1029.

Ögel ZB, Yüzügüllü Y, Mete S, Bakir U, Kaptan Y, Sutay D, Demir AS. 2006. Production, properties and application to biocatalysis of a novel extracellular alkaline phenol oxidase from the thermophilic fungus Scytalidium thermophilum. Applied Microbiology and Biotechnology. 71(6): 853-862.

Pavan ME, López NI and Pettinari MJ. 2019. Melanin biosynthesis in bacteria, regulation and production perspectives. Applied Microbiology and Biotechnology.

Pellegrini N, Simonetti P, Gardana C, Brenna O, Brighenti F, Pietta P. 2000. Polyphenol content and total antioxidant activity of Vini novelli (Young red wines). Journal of Agricultural Food Chemistry. 48(3): 732-735.

Re R, Pellegrini N, Proteggente A, Pannala A, Yang M, RiceEvans C. 1999. Antioxidant activity applying an improved ABTS radical cation decolorization assay, Free Radical Biology and Medicine. 26(9): 1231-1237.

Rice-Evans CA, Miller NJ, Paganga G. 1997. Antioxidant properties of phenolic compounds. Trends in Plant Science. 2(4): 152-159.

Serafini M, Ghiselli A, Ferro-Luzzi A. 1996. In vivo antioxidant effect of green and black tea in man. European Journal of Clinical Nutrition. 50(1): 28-32.

Sevindik M, Akgul H, Pehlivan M, Selamoglu Z. 2017. Determination of therapeutic potential of Mentha longifolia ssp. longifolia. Fresen Environ Bull, 26(7): 4757-4763.

Silva RFM and Pogačnik L. 2020. Polyphenols from Food and Natural Products: Neuroprotection and Safety. Antioxidants, 9(1): 61

Soyler UB. 2012. Characterization and analysis of the antioxidant capacity of functional phenolics oxidized by Scytalidium thermophilum catalase-phenol oxidase (CATPO). PhD. Thesis, Middle East Technical University, Ankara, Turkey.

Yuzugullu Y, Trinh CH, Smith MA, Pearson AR, Sutay-Kocabas D, Phillips SEV, Bakir U, Ogel ZB, McPherson MJ. 2013 Crystal structure, recombinant expression and mutagenesis studies of the bifunctional catalase-phenol oxidase from Scytalidium thermophilum. Acta Crystallographica Section D: Biological Crystallography. 69: 398-408.

Xiao-Lu T, Ning C, Xing-Guo X. 2016. Identification of a catalase-phenol oxidase in betalain biosynthesis in red Amaranth (Amaranthus cruentus). Frontiers in Plant Science. 6: Article 1228.

Xu F. 2005.Applications of oxidoreductases: Recent progress. Industrial Biotechnology. 1(1): 38-50.

Zamocky M, Gasselhuber B, Furtmüller PG, Obinger C. 2012. Molecular Evolution of hydrogen peroxide degrading enzymes. Archives of Biochemistry and Biophysics. 525: 131-144.

Zhao CN, Tang GY, Cao SY, Xu XY, Gan RY, Liu Q, Mao QQ, Shang A, Li HB. 2019. Phenolic Profiles and Antioxidant Activities of 30 Tea Infusions from Green, Black, Oolong, White, Yellow and Dark Teas. Antioxidants. 10;8(7):215. 